\title{
DESIGN AND DEVELOPMENT OF ROWING BIKE TO OPTIMIZE COST
}

\author{
Adesh D. Ingale ${ }^{1}$, Prathamesh V. Thorve ${ }^{2}$, Yogesh S. Khairnar ${ }^{3}$, Pavan R. Tiwari ${ }^{4}$
}

Student of Mechanical Engineering, D. Y. Patil College of Engineering, Pune, Savitribai Phule Pune University, Pune, Maharashtra, India

Guide - Prof. Swati Dhamale

\section{ABSTRACT}

In our day-to-day life, we all have seen bikes, cycles. Some work on diesel, petrol while some work on physical efforts. Regular exercise is not possible for many people so we have innovated this row bike which is different from the other cycles. Regular Cycles help in exercising the lower side of the body but this row bike can exercise you a whole body workout. This row bike can be used by all the sportsmen who are always craving fitness. The mechanism used in this project is seen in the Gymnasium all the time, what we called it a rowing machine and the second thought is the process of rowing a boat. The action steps mentioned further continue the transmission process and drive the bike forward or transmit power to the rear wheel, we have used a coil spring to rotate the wheel, and power is transmitted.

Keywords: Design, 3D Modelling, Manufacturing, Material Selection, Rowing Bike

\section{INTRODUCTION}

A rowing bike is an idea came fore from a rowing mechanism used in a gymnasium. It is the same as rowing boat action. People go to the gyms for fitness and pay lots of money, this rowing bike can be a very good alternative for a very low amount. The traditional type of cycle can give a workout to the only lower part of the body whereas this rowing bike can work out the whole body muscles which will keep all the people physically fit and fine. It's very helpful for people who are craving for fitness. Regular exercise will keep health issues away. This project's manufacturing are done completely from scrap to a quality product. The mechanism used in this design is very simple so that it is economical and can be easily taken into consideration. Even after a decade, it can have ample modifications and can develop in more numbers and even can replace the traditional bicycles and gymnasiums types of equipment. The product is already available in the market but is not so popular and affordable price and better stiffness and strength so that it can give a quality added value for the future.

\section{METHODOLOGY}

In this project, we have divided the whole methodology into two different parts to make it easy to understand 1) parts to be manufactured by our own 2) parts to be purchased. In the whole project work, we have started from the scrap and made a cost-effective and efficient project that will help all the regular people and people who crave fitness. So we started this project with a rough design and then Modeled it in Creo software which gave it a very realistic look then and then after applying calculation we got to know about its strength and the load it can carry in short we made it acceptable from all the condition

\subsection{PROBLEM STATEMENT}

To design and fabricate a rowing bike to optimize the cost. The bike that we are manufacturing will be of low cost as compared to bikes present in the market

\subsection{OBJECTIVES}

1) To fabricate good quality row bike at having low cost.

2) To develop a rowing bike that will provide exercise to our whole body.

3) Should be simple to drive. 
4) Developing aesthetic row bikes for modern use.

\subsection{MATERIAL SELECTION}

Whenever we design any product, machine, material selection is a very important step to follow.

1. We are always stuck in the step of material selection during the manufacturing process that what should be the material that will give us strength ani economy as well. What should I use, ceramic, plastic, wood, or metal? Every design machine or part should have the required stiffness and strength

\section{Stiffness and Strength}

2. As if we consider our rowing bike design, there is a frame called a truss that can withstand a very high load without any kind of deflection. As we look into the wheel, it has spokes that will provide it with sufficient stiffness so that the wheel cannot buckle. A good stiffness will give a very satisfactory result in its operation. In our project, we are using an aluminum frame, Some other accessories, and a coil spring to transmit power to the rear wheel.

3. Shafts A shaft could be a rotating device component, sometimes spherical or circular in the cross-section, this can be accustomed to transmit strength from one side to a different, or from a tool that produces strength to a tool that absorbs strength.

4. Bearings are the mechanism that helps to reduce friction and provide a smooth operation between the two surfaces and it also reduces energy consumption.

5. Wheels- wheels are the main parts of the vehicle, it should be of very good quality because wheel tyres come in contact with the road and wear out due to friction. Spokes are provided to the wheels to provide better stiffness and strength to the design

6. Rope wire - Rope wire or a wire rope is a rope having high stiffness and strength which is used for much high weight pulling and weight lifting purposes in a controlled manner.

7. Sprocket Wheel - Sprocket wheels are the simple circular disc-like structure having teeth on their periphery and is used to provide transmission to the wheel

8. Other accessories - For the complete designing and manufacturing of the product, some standard elements or products which are difficult to manufacture on some levels are required those are nuts, bolts, brakes, coil springs, wire, tyres, wheels,

\subsection{FUNCTIONAL REQUIREMENTS}

1) Bike should provide a good amount of exercise

2) Should have a smooth start and stop operations.

3) Size should be the same as a normal bicycle.

4) To maximize the human effort for better exercise.

\subsection{WORKING OF ROWING BIKE}

The Rowing bike consists of the following main parts :

1) Frame

2) Seat

3) Tyres

4) Handlebar

5) Fork

So, the rider will sit on the bike on the seat which can slide along the way provided on the frame. And he will put one leg on the front footrest for balancing and when the bike is in motion he will put both legs on the footrest. Then the next step is to pull the handlebar towards the chest which will give transmission to the rear wheel and the combined action of pulling the handlebar and the sliding of the seat will make the bike move forward. The pulling handlebar will rotate the rear wheel with the help of a coil spring which will release energy and give motion to the rear wheel so that the bike will move forward. The actions which are evolved in the bike riding process is given

1) The catching step

2) The driving step 
3) The finishing step

4) The recovery step

\section{MODELLING}

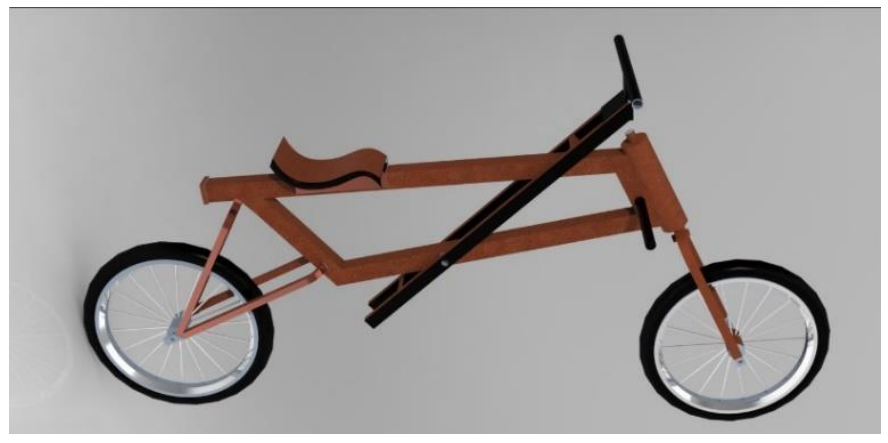

3D CREO MODEL

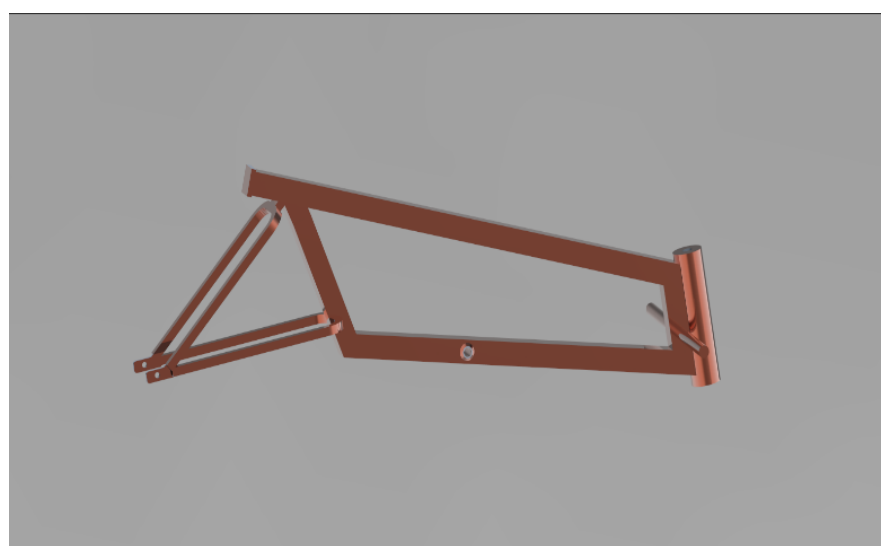

FRAME

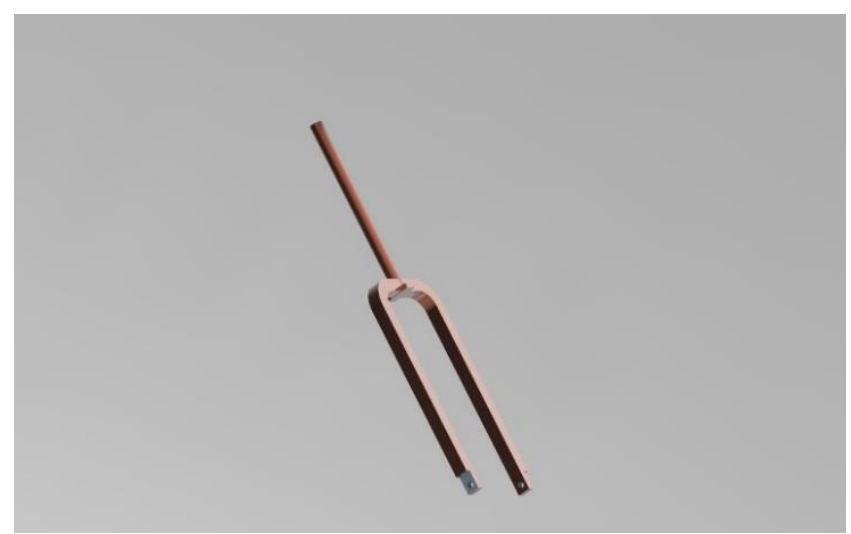

HANDLE FORK

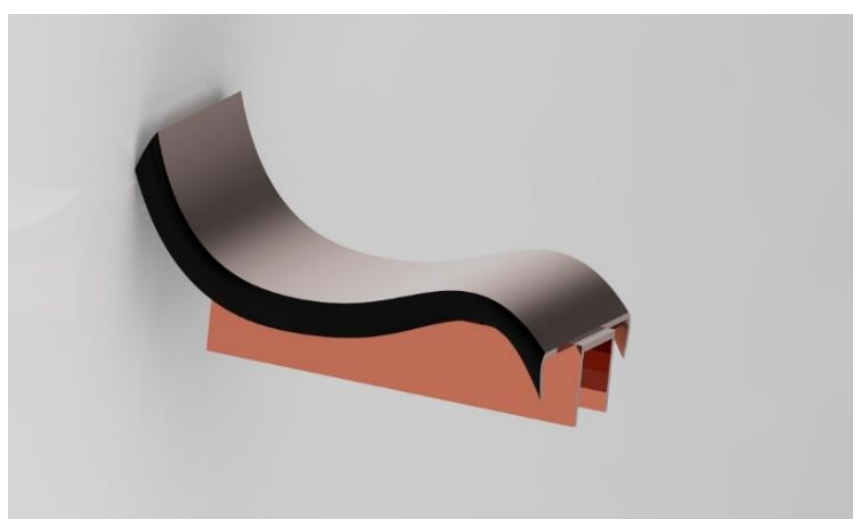

SEAT

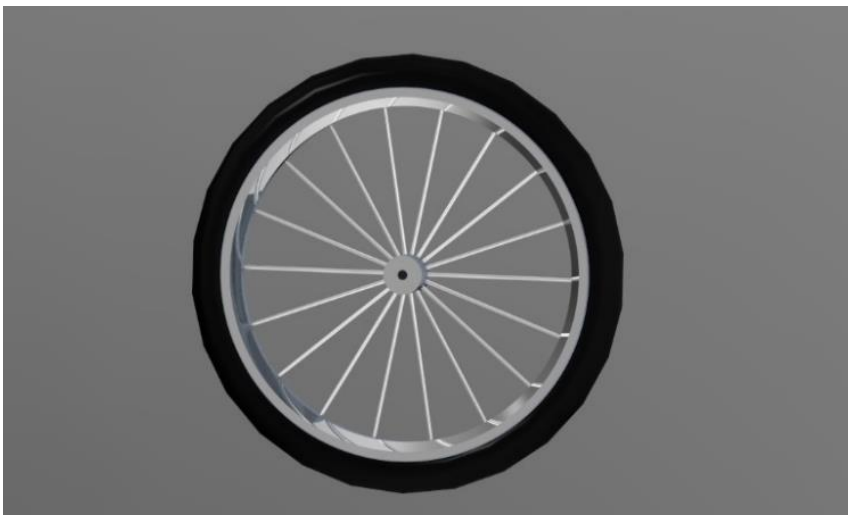

TYRE

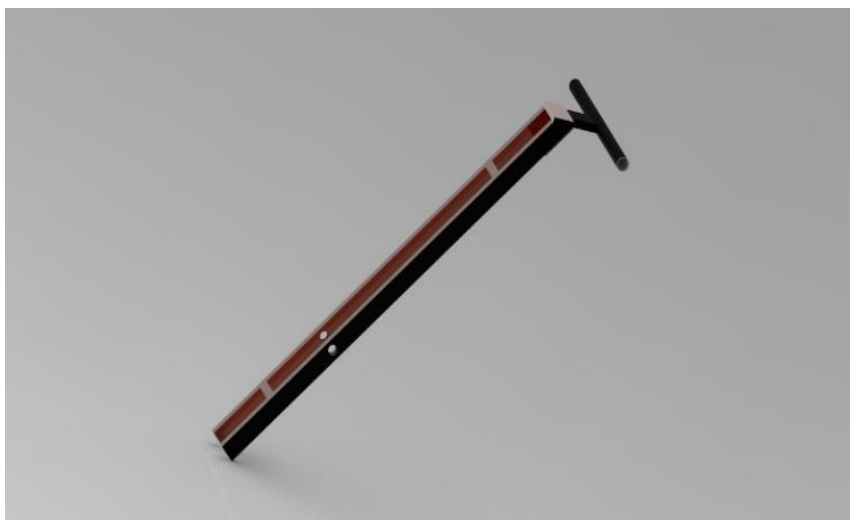

HANDLE BAR 


\section{RESULTS AND DISCUSSION}

\section{Driving Force by human}

Let's say Linkages having cross section $=300 * 100$ $\mathrm{mm}$

$\mathrm{I}=\mathrm{bd}^{3} / 12$

$\mathrm{Y}_{\max }=\mathrm{d} / 2$

$\mathrm{Z}=\mathrm{bd}^{2} / 6$

$\mathrm{B}=300 \mathrm{~mm}$

$\mathrm{D}=100 \mathrm{~mm}$

$\mathrm{Z}=\left(300 * 100^{2}\right) / 6$

$\mathrm{Z}=500000$

$\mathrm{Z}=5^{*} 10^{5} \mathrm{~mm}^{3}$

Let's normal human being can pull a weight at a force of $150 \mathrm{~N}$ in sitting position

Therefore,

Selecting an $300 * 100 \mathrm{~mm}$ cross section for the link.

\section{Design of shaft}

Lets check for EN 24 using PSG design data book

Having Ultimate tensile strength $800 \mathrm{~N} / \mathrm{mm} 2$

Yield Strength 680 N/mm2

Now,

Fs $\max =0.3 \mathrm{fyt}$

$=0.3 * 680$

$=204 \mathrm{~N} / \mathrm{mm}$

By Considering minimum forces,

Fs $\max =144 \mathrm{~N} / \mathrm{mm} 2$

This is the value allowable of shear stress for safe operation.

\section{Selection of Bearing}

Here,

Let radial force be $198.54 \mathrm{~N}$

Shaft $=600 \mathrm{rpm}$

Life of the bearing be $10000-20000 \mathrm{hr}$.

Diameter of the shaft $40 \mathrm{~mm}$

Bearing life in million revolutions:

$\mathrm{L} 10=60 \mathrm{~nL}_{10} \mathrm{~h} / 10^{6}$

$=60(600)(30000) / 10^{6}$

$=600$ million revolutions

Now,

Dynamic Load carrying capacity:

$\mathrm{C}=\mathrm{P}(\mathrm{L} 10) 1 / 3=3000(1080) 1 / 3=1674.60 \mathrm{~N}$

Therefore, according to PSG design data book,

Design number 6003 having ISI no 17AC03 with

$\mathrm{d}=17$

$\mathrm{d} 1=19$

$\mathrm{D}=35$

D2=33

$\mathrm{B}=10$

Basic capacity $\mathrm{N}=2850$ to 4650

\section{Working of Rear Mechanism}

When the rope is pulled cycle will move in the forward direction. And further spring will retain handle to its initial position. In this way, the cycle will move in the forwarding direction when the handle is pulled backward and released freely.

Here, $P=$ force which is induced in the outer end side $A$ because of arbor winding $\mathrm{N}$ 
$r=$ center of gravity distance of spiral from its outer end side

$\mathrm{t}=$ thickness of the given strip in $\mathrm{mm}$

$b=$ perpendicular width of the spring

I= length of the spring from outer side to the inner side

here,

the maximum bending moment can be given by:

$M_{b}=P(2 r)$

The maximum bending stress induced can be calculated as

$\sigma_{b}=M_{b} y / l$

here

$M_{b}=2 M$

$\mathrm{Y}=\mathrm{t} / 2$

$\mathrm{l}=\mathrm{bt}^{3} / 12$

Therefore,

$\sigma_{\mathrm{b}}=12 \mathrm{M} / \mathrm{bt}^{2}$ $. \mathrm{N} / \mathrm{mm}^{2}$

at both ends, angle of rotation can be given by

$\theta=\mathrm{MI} / \mathrm{El}$

$12 \mathrm{Ml}^{2} \mathrm{Ebt}^{3}$

Now,

Deflection $\delta=r \theta$

$$
\delta=12 \mathrm{Mlr} / \mathrm{Ebt}^{3}
$$

finally,

strain energy stored in that flat torsion spring can be given by:

$U=1 / 2 * M \theta=1 / 2 * M\left(12 \mathrm{Ml} / \mathrm{Ebt}^{3}\right)$

$\mathrm{U}=6 \mathrm{M}^{2} \mathrm{I} / \mathrm{Ebt}^{3} \quad$......... ( Joule )

\section{CONCLUSION}

After this project, we can conclude that we had achieved our objectives. our main motto is to provide the best quality rowing bicycle at minimum cost as possible as and current cost of this bicycle is 50,000 rs. in India we build this rowing bike for under 12,000. Apart from that rowing bicycles gives great results while riding. rowing bicycle provides Proper exercise for the upper body. Our project was carried out to provide people with a new vehicle that is energy efficient, eco-friendly, economically affordable, and also helps to play role in safeguarding the mother earth

\subsection{ADVANTAGES}

1. There is a frame in which driving the cycle while lying down to get comfortable seating and a footrest

2. Rowing bicycle can be handled easily

3. Rowing bike provides a full-body workout

4. Less cost

5. Light in weight

6. New steering mechanism is used in which sleeved cable is used to steer the cycle

\subsection{FUTURE SCOPE}

1) In some years, instead of paying lots of money for gyms, they will prefer Rowing bike

2) It will be beneficial for sportsmen

3) By considering the benefits and affordability, it can be added to bike racing at the national or international level

4) Can be worked on adding gears for speed variations

5) Can be one of the affordable and best ways to work out over all other gym equipment. 
6) It will help to keep people physically fit if used worldwide after a decade and also reduce pollution.

7) This mechanism can be introduced in other mechanical models as well for advancement.

8) Because of its various benefits rowing bike can be introduced in national and international outdoor sports.

9) We can make modifications to the seat for a comfortable seating position.

10) Can be made using three wheels for disabled persons.

11) This bike would be a beneficial way of exercise compared to costly gym equipment.

12) When the rowing bicycle is available at affordable cost, customer and services provider both will get the benefit

13) Much more possibilities that in upcoming 5-10 years rowing bicycle acquire major market compared to a normal bicycle

\section{REFERENCES}

[1] Reddy, G. Sreeram, Manzoor Hussian, and K. Srinivasa Rao. "Latest analysis on Reverse Engineering Technology.“

[2] International Journal of Advanced engineering.SSN 2250-3234 Volume eight, \#1 (2018) 55-62

[3] Rowe, T., M. L. Hull, and E. L. Wang. "A pedal measuring device for cross-country cycling."

[4] 8. Devaiah, B. B., et al. "Stress analysis of a bicycle frame." Materials Today: Proceedings five.9 (2018): 18920- 1892 